soothed; and then they recover. It is well-known that certain lesions of the brin, or internal parasites, cause animals to turn incessantly round and round, either to the right or left, sometimes accompanied by a backward movement: and $I$ have just read, through the kindness of Dr. Brunton, the account given by Mr. W. J. Moore (Indian Medical Gazette, Jan. and Feb 1873) of the somewhat analogous result which followed from pricking the base of the brain of a pigeon with a needle. Birds thus treated roll over backwards in convulsions, in exactly the same manner as do the ground-tumblers; and the same effect is produced by giving them hydrocyanic acid with strychnine. One pigeon which haả its brain thus pricked recovered perfectly, but continued ever afterwards to perform summersaults like a tumbler, though not belonging to any tumbling breed. The movement appears to be of the nature of a recurrent spasm or convulsion which throws the bird backwards, as in tetanus; it then recovers its balance, and is again thrown backwards. Whether this tendency originated from some accidental injury, or, as seems more probable, from some morbid affection of the brain, cannot be told ; but at the present time the affection can hardly be called morbid in the case of common tumblers, as these birds are perfectly healthy and seem to enjoy performing their feats, or, as an old writer expresses it, "showing like footballs in the air." The habit apparently can be cortrolled to a certain extent by the will. But what more particularly concerns us is that it is strictly inherited. Young birds reared in an aviary wh ch have never seen a pigecn tumble, take to it when first let free. The habit also varies much in degree in different individuals and in different sub-breeds; and it can be greatly augmented by continued selection, as seen in the house-tumblers, which can hardly rise more than a foot or two above the ground without going head over heels in the air. Fuller details on tumbler-pigeons, may be found in my "Variation of Animals under Domestication," vol. i. pp. 150, 209.

In conclusion, from the case of neuter insects, of certain reflex actions, and of movements such as those of the tumbler-pigeon, it seems to me in the highest degree probable that many instincts have originated from modifications or variations in the brain, which we in our ignorance most improperly call spontaneous or accidental ; such variations having led, independently of experience and of habit, to changes in pre-existing instincts, or to quite new instincts, and these proving of service to the species, have been preserved and fixed, being, however, often strengthened or improved by subsequent habit.

With regard to the question of the means by which animals find their way home from a long distance, a striking account, in relation to man, will be found in the English translation of the Expedition to North Siberia, by Von Wrangell. He there describes the wonderful manner in which the natives kept a true course towards a particular spot, whilst passing for a long distance through hummocky ice, with incessant changes of direction, and with no guide in the heavens or on the frozen sea. He states (but $I$ quote only from memory of many years standing) that he, an experienced surveyor, and using, a compass, failed to do that which these savages easily effected. Yet no one will suppose that they possessed any special sense which is quite absent in us. We must bear in mind that neither a compass, nor the north star, nor any other such sign, suffices to guide a man to a particular spot through an intricate country, or through hummocky ice, when many deviations from a stright course are inevitable, unless the deviations are allowed fur, or a sort of "dead reckoning" is kept. All men are able to do this in a greater or less degree, and the natives of Siberia apparently to a wonderful extent, though probably in an unconscious manner. This is effected chiefly, no doubt, by. eyesight, but partly, perhaps, by the sense of muscular movement, in the same manner as a man with his eyes blinded can proceed (and some men much better than others) for a short distance in a nearly straight line, or turn at right angles, or back again. The manner in which the sense of direction is sometimes suddenly disarranged in very old and feeble persons, and the feeling of strong distress which, as I know, has been experienced by persons when they bave suddenly found out that they have been proceeding in a wholly unexpected and wrong direction, leads to the suspicion that some part of the brain is specialised for the function of direction. Whether animals may not possess the faculty of keeping a dead reckoning of their course in a much more perfect degree than can man; or whether this faculty may not come into play on the commencement of a journey when an animal is shut up in a basket, I will not attempt to discuss, as I have not sufficient data.

I am tempted to add one other case, but here again I am forced to quote from memory, as I have not my books at hand. Audubon kept a pinioned wild grose in confinement, and when the period of migration arrived, it became extremely restless, like all other migratory birds under similar circumstances; and at last it escaped. The poor creature then inmediately began its long journey on foot, but its sense of direction seemed to have been perverted, for instead of travelling due southward, it proceeded in exactly the wrong direction, due northward.

CHARLES DARWIN

\section{UNIVERSITY OARS}

II.

WE resume our remarks at the poins at which we left off last week, i.e. the uncomfortable one of the killed and wounded in the great annual battles on the Thames.

Of the 294 men who rowed in the 26 races taking place between the years 1829 and 1869 (both inclusive), 39 men have died, or rather we should say 40 , for one other death has occurred, apparently since the introductory portion of the work was written, and the tables in the appendix were compiled, and we are assured on the authority of elaborate statistics and the logic of averages, that, in comparison with other portions of the civil community, this is a very moderate death-rate. Of the diseases which have carried off in youth or early manhood these 40 men, we will only instance one kind, as being the only one with which boat-racing can presumably be connecied, namely consumption;, "and other diseases of the chest:" to these perhaps may be added "heart affections." Of the former there are 9, of the latter 3 , in all 12. We are assured, again, that this percentage is a mode- 
rate one, that these ailments are still more exacting, not only with other portions of the "civil community," but also with the seamen of the Royal Navy, and with the men who fill the ranks of the army, and notably so of the Guards ; it being notorious that men of tall stature are more liable to be attacked by, and less able to resist, diseases of this nature than men of more compact build. But here we must confess that this portion of the book does not leave upon our minds quite so comfortable an impression as we could desire. It is felt throughout that the parties compared have little in common in the essentials that make such comparisons valuable. True the University Oars as a rule are tall, above the average height even of men in their own rank of life ; but they are "picked" men-picked for strength as well as staturepicked for physical power already proved-whose whole life from infancy up to manhood has been one varied series of all that art, nature, and science could bring to bear favourably upon their growth and development. While on the other side do we not find the reverse of these conditions prevailing? does not the author himself, elsewhere, describe with painful emphasis the wretched forms, stunted frames, unhealthy occupations and debasing habits of a large portion of the "civil community;" and is it not notorious that soldiers in regiments where height of stature is the chief requisite, were probably throughout their growing time subject to privations in food and clothing and housing, which coupled with rapid growth, and their surroundings after enlistment, presented the very conditions most favourable to the development of the diseases in question?

While expressing an opinion of qualified satisfaction with the comparisons instituted, we can in no way question the accuracy of the figures given ; but we must record our feeling, which we believe will be one generally felt, that such evidence fails in accomplishing the purpose for which it was advanced.

We have stated our belief that, could the truth be ascertained, as many or more injuries would be found to have occurred in the same space of time (a similar number of men having been so engaged) in hunting, at foot-ball, or at cricket; probably too as many of these injuries would have proved fatal. But in stating this we are brought face to face with the fact that, in all instances of hurt or of injury so sustained, they would arise from accidents. But this is not the case with the injuries which spring from Boat-racing; here, be they trifling or be they severe, be they few or be they many, they seem to the natural outcome of the exercise itself; not a hurt, in a sense in which we commonly use that word, of bruise, or break, or strain, and to which we may apply support or remedy, but an unknown evil, unfelt, unsuspected, at the time, but to which existence has been given-to be developed in after-life, when we least suspect it, and are least able to cope with its advances. Now the question which presents itself here to us, and must present itself to any one who cares for the continuation of this favourite exercise and yet would free it from this grave drawback-is this: Are these injuries, these evils inevitable? Yes, we answer, at once, and without reservation or qualification, to two points of misconception only is hurt or injury in these contests to be attributed: correct these and this exercise will stand out at once, relieved from all let or hindrance, free, freer than any other, because it is exempted from the accidents that lie in the path of others. Correct these, and the tripartite list which Dr. Morgan has supplied of benefited, uninjured, and injured, would be transformed into one uniform list of the first-mentioned only, for every one would be benefited who pursued this pastime.

In the contest which took place on the Thames last week the points which would probably strike an ordinary spectator most forcibly would be these:-first, the length of the course (four and a quarter miles), and second, the shortness of the time in which the boats covered the distance (not quite 20 minutes), and he would probably think that the first was too long, and if he did not actually think that the second was too short (for who admits that a race can be run or rowed too quickly?), he would marvel all the same at its performance, and wonder how. men could propel a boat over such a long course in such a short space of time. Whether the course could be shortened with advantage, and yet sufficiently test the crews, we will not here discuss, although we think it is open to discussion ; and how it is possible to propel a boat over it in the above-mentioned time, is only to be expldined by one means, i.e., by a critical examination of the boat itself, and, let us add, a glance at its crew. In the latter he will see eight as fine young men as he probably ever saw in his life before; in the former he will see a machine bearing no resemblance to anything he ever saw afloat, either on river, lake, or sea, or possessing in shipe, or size, or bulk, or weight, any of the proportions which other boats possess: so slim for its leng $h$, so straight, so sharp! constructed at all points to cleave the water like a knife-blade! fitted out at all points to save every fraction of weight in rowing or steering gear, to utiitse and concentrate every ounce of propelling power exerted by the oarsmen from stroke to bow.

Now although the perception of this may to some extent explain the extraordinary rapidity of the race, it will not remove from the spectator's mind the idea of its severity. To him it will still appear that the work will have been tremendous, and he is right: the work was tremendous, though not perhaps in the manner or of the kind which he imagines, or of what is commonly understood when the word work is used.

"In rowing, as in some other exercises, where the voluntary muscles of the trunk and of the upper limbs are engaged, the breath is "held" in the lungs during the muscular effort, in order to keep the chest distended, or firm, or as it is technically called, "fixed," that these muscles may have firm and unyielding points of attachment during the contractile efforts-fixed fulcra for their levers; and when this is prolonged or repeated over any considerable space of time, it becomes a highly disturbing influence to respiration, and doubly so if the exercise be one which greatly augments the respiratory requirement; for the act of fixing the chest is accomplished by retaining the chest at its point of expansion, when in the natural order of respiration it would be collapsing. And while in ordinary effortless breathing, or in exercises where the lower limbs are solely or chiefly employed, such as walking or running, the inspiration and expiration follow each other in uninterrupted successioneach occupying about the same space of time as the other, 
and the two constituting the entire process-in rowing, both these acts are hurried over during that time in which the muscles are relaxed, i.e, towards the close of the stroke, and on the rapid forward dart of the body preparatory to another; when the breath is again held and the chest fixed during the muscular effort. Now in ordinary breathing the rate is, to a full-statured man, from 16 to 20 inspirations per minute, while the racing pace is 40 per minute, or more, and we have seen that the breathing is regulated by the stroke, a breath for each, and these are at 40 a minute! But we have also seen that although there is a breath for every stroke, still the double process of inspiration and expiration does not occupy the whole of even this brief space of time, being accomplished during the momentary muscular relaxation towards the end of the stroke and the forward reach of the body preparatory to another, greatly augmenting the rate at which this double process is performed." Truly the spectator was right in thinking a boat-race to be tremendous work, for so it is, as regards heart and lungs, at any rate.

And now with reference to the second aspect of boatracing, its demands upon the muscular energies of the body, the aspect which probably the spectator had in view when impressed by the probable amount of "work" of the race. Now will he be relieved or will he be disappointed to learn that the work to be done, the muscular exertion to be undergone, is very slight indeed,-certainly not more than, if so much as, was undergone by any one of the thousands who ran the distance shouting on the banks. Perhaps his examination of the boat and boating gear has prepared bim for some such revelation, perhaps it has not, but we can assure him that its accuracy has been proved, not only by our own long personal observations of its mode of action and consequent results upon the frames of the men themselves, but by practical and theoretic tests of the most searching kind, instituted by men of unquestionable ability for the office, and of unquestionable freedom from prejudice or bias.

We have doubted whether this would be a relief or a disappointment to the ordinary spectator ; nor have our doubts been restricted to him. Others whose practical knowledge of the art and exercise of rowing is great have also found it embarrassing how to receive this announcement. For ourselves, we regard it as an evil, although not one without a remedy. But not only is the muscular effort altogether disproportionate to that of the organs of circulation and respiration, but inadequate in its amount to develop and sustain to their full capacity the frames of the men engaged therein, when rowing is practised for exclusive exercise: it is found that this muscular exertion, inadequate as it is, is also very irregularly and partially divided, very unequally distributed among the several portions of the body. Thus, we quote again from our former source :-

"A little examination will prove, I think, what at first may not have been surmised, that the legs have the largest share of the work in rowing, for whlle all other parts employed, back, loins, and arms, act somewhat in detail and in succession, the legs act continuously throughout the stroke, and the individual efforts of each, and the concentrated efforts of all the other parts of the body employed are transmitted through them to the point of resistance-the stretcher. .... It will be found also that the stroke is nearly finished before the contractile efforts of the arms are in any degree engaged, namely, when the trunk reaches the vertical line, and they are called in to finish the stroke, and to turn and run out the oar on the forward reach of the body preparatory to another. Rowing thus gives employment to a large portion of the back, more to the loins and hips, and most of all to the legs; but it gives little to the arms, and that chiefly to the fore-arm, and least of all to the chest."

At this point Dr. Morgan's views and our own do not run quite parallel, but the divergence is not so great as at first sight may appear, and almost seems the expression of the impatience of the Oarsman at anything which might be construed as a hint that rowing had a fault or a defect of any kind whatever, than the decision of the Physician on a question which he had considered. It may be a loss sometimes, perhaps, to have more qualifications than one for judging or writing on a given subject. Thus we recognise the physician when he admits the importance of the development of the chest by muscular exertion, admits that in so doing we do not merely increase its muscular coverings, but actually expand the walls of the thoracic cavity, giving ample space for the organs contained therein to perform their all-important functions, nay, that these organs themselves are endowed with increased bulk, vigour, and power by the same means : but here the oarsman crops up, and he contends that all these good things are to be obtained by practice at the oar, for that rowing does give this invaluable muscular exertion to the chest. Again, we recognise the physician, acknowledging the substantiated facts of physiological inquiry when he admits that the chest receives its muscular action through the arms; but again the oarsman contends that in rowing the arms $d o$ have energetic work to perform adequate to this task; nay, that in his own experience, when captain of his college boat, "he has seen the biceps expand and the forearm increase in girth ;" the latter probably, but the former-well, they must have rowed in very bad style to cause this development! But scarcely is this avowal made when some doubt as to the propriety of the admission seems to be felt, and the subject is disposed of by the following remark. "This is an inquiry which I do not mean to inflict upon my readers. It is of more interest to the student of anatomy than to the general public," probably this is the case, possibly it is not of great interest to either, but how about the rower? It is with him we are now concerned, and we opine it is to him of very great importance indeed.

While we are engaged in fault-finding we will go as far as the paragraph following that from which we have just quoted, and in which we find the same kind of partial reasoning. He proceeds to say :-

"Let us then consider in what way the chest is affected by bodily labour, when the muscles are called into activity, whether in rowing, or running, or in such a course of gymnastics as is now wisely required for young recruits. We find that, in the first place, the parts more especially exercised acquire additional bulk, grow both larger and stronger; and secondly, we observe that the circumference of the chest is increased, it becomes wide: and deeper. I have looked over numerous statistics so tabulated as to show the physical value of gymnastic instruction, and these tables all agree in showing that there is under such circumstances a coincident development both of muscle and of chest." 
No doubt "the statistics so tabulated " give the results which the author has seen, for are not such statistics, after being inspected by the medical officers of the army, regularly forwarded to the Adjutant-General of the forces for his information? but what has this to do with boatracing or running? These three exercises are as different in character and as different in their demands upon the physical energies of the human body in their practice, and in the results of their practice, as it is possible to conceive; and who that had investigated these three modes of muscular exertion would thus run them together for the purpose of showing their value or the results of their practice on the development of the chest? If the development of the chest is mainly due to the muscular exertions of the arms, how can running develop it, unless a man run upon "all fours ?" When organising this "course of gymnastic instruction for recruits," we held ever before us a principle precisely the opposite to that which regulates either good running or rowing. In these, sameness of action, from the start till the close of the exercise, prevails; in the gymnastic course it is variety, the course embracing several hundreds of exercises, requir ing different degrees of efort, executed at different rates of speed, employing every portion of the frame, and notably the upper limbs and trunk of the body-exercises all tested and proved to accomplish given results, on thousands of men, and over many years of careful observation, long before they were embodied by us in our military system. These three exercises should be estimated each by itself, and allowed to stand on its own feet. No real or permanent advantage can accrue to any of them by being thus lumped together, the more especially as they are in their nature so dissimilar.

ARCHIBALD MACLAREN

\section{THE EARTH}

The Earth: a Descriptive History of the Phenomena of the Life of the Globe. 2 vols., with numerous maps and illustrations.

The Ocean, Atmosphere, and Life. Being the Second Series of a Descriptive History of the Phenomena of the Life of the Globe. 2 vols., with numerous maps and illustrations. By Elisée Reclus. Translated by the late B. B. Woodward, M.A., and edited by Henry Woodward, British Museum (Chapman and Hall I87r and 1873.)

I.

$\mathrm{T}$ is at length beginning to be acknowledged on all 1 hands that no system of education can be pronounced perfect without a recognised position being assigned to the study of science. It cannot, of course, be supposed that in the ordinary curriculum, say of a university education, the various subjects of scientific study can obtain that exclusive attention which is required, in order to master them; but it is of the highest importance that, by the introduction and use of suitable text-books, the mind of the youthful and ardent lover of Nature in her various phases should be directed and prepared for entering upon those more minute studies and exhaustive researches in reference to particular subjects in the wide field of scientific inquiry, by which alone he can hope to force Nature to disclose her secrets.

Such a textbook we have in the work now before us -for these four volumes really form one entire work-a most admirable translation of a treatise on the earth and its phenomena by the eminent French savant, M. Elisée Reclus, the result of more than fifteen years' careful study, travel, and research. The translation is by the late Mr. B. B. Woodward, the Qucen's librarian at Windsor Castle, and edited since his death by his brother, Mr. Henry Woodward, of the British Museum. Notwithstanding the editor's apology, the work suffers but little from its appearance in an English dress; in fact, the translation has been carried out with such remarkable success, that it possesses all the merits of an original English work. The constitution and phenomena of the planet in which we live are subjects of the deepest interest and importance to us all, and, to the earnest and thoughtful seeker after knowledge, present marvels on a scale of grandeur and magnitude far beyond the comprehension of the mere superficial observer. As M. Reclus says :--

"True enough that the earth is nothing but an almost impalpable grain of dust to the vision of the astronomer scanning the nebulx in the field of his telescope, but it is, 